\title{
Um verbete jamais publicado na Enciclopédia: "História", de Marmontel
}

\section{A Never Published Entry in the Encyclopédie: Marmontel's "History"}

\section{Daniela Kern}

daniela.kern@ufrgs.br

Professora adjunta

Universidade Federal do Rio Grande do Sul

Rua Senhor dos Passos, 248

90020-180 - Porto Alegre - RS

Brasil

Palavras-chave

História da historiografia; História da França; Historiografia francesa.

Keywords

History of historiography; France history; French historiography. 
Enciclopedista, dramaturgo, poeta, contista, romancista, historiador e filósofo que obteve grande reconhecimento na Europa do Século das Luzes, Jean-François Marmontel (1723-1799), ${ }^{1}$ em meados da década de 1750, era um dos frequentadores do célebre Salão Holbach, ponto de encontro de intelectuais iluministas como Diderot, Rousseau, Melchior Grimm, Helvetius, Buffon e Morellet. De Diderot, em especial, tornou-se amigo. A pedido dele e de outro amigo ainda mais próximo, d'Alembert, passou a colaborar com artigos sobre literatura para a Enciclopédia. O projeto da Enciclopédia enfrentou uma série de obstáculos, e a colaboração teve de ser interrompida. No entanto, conforme destaca Cardy (1978), Marmontel continuaria contribuindo com outros projetos de enciclopédia, como o Supplément de l'Encyclopédie (1776-1780) e a Encyclopédie Méthodique (1782-1832). Sua colaboração na área da literatura se justificava, entre outros motivos, pelo respeito de que então gozava como dramaturgo. O grande sucesso da estreia, obtido com a peça Denys le Tiran (1748), seria repetido anos mais tarde, com Bélisaire (1767). Ao explorar o drama do guerreiro bizantino que, sob as ordens do imperador Justiniano (483-565), fora supliciado e ficara cego, Marmontel pretendia combater a intolerância religiosa, como ele mesmo deixou claro mais tarde, em suas Memórias: "É aos negros fantasmas da superstição, é aos monstruosos horrores do fanatismo que Belisário recusa sua crença" (MARMONTEL; TOURNEAUX 1891, p. 290). Tal projeto de combate à intolerância seria retomado com a publicação, em 1778 , da novela Les incas, na qual corroborou o ponto de vista de Las Casas ao condenar veementemente a perseguição dos índios da América pelos colonizadores europeus.

Paralelamente à carreira literária, Marmontel galgou diversas posições no Ancien Régime, que demandavam sua atuação, seja como homem de letras, seja como historiador: foi nomeado Secrétaire des Bâtiments du Roi em 1753, membro da Académie Française em 1763, historiógrafo da França em 1771, secretário perpétuo da Académie Française em 1783, Historiographe des Bâtiments em 1785 e, por último, catedrático de História no recém-criado Lycée, em 1786.

No ano de 1787, com uma carreira polivalente nas áreas de Literatura e História já estabilizada, Marmontel reúne, em Élemens de Littérature, ${ }^{2}$ o conjunto de verbetes sobre literatura que havia publicado nos vários projetos de enciclopédia dos quais participara. A esses acrescenta mais alguns novos, caso de "História". Que um verbete sobre história figure entre outros tantos sobre literatura é fato digno de nota, e essas aproximações disciplinares se

\footnotetext{
${ }^{1}$ Tendo em vista que a fortuna crítica de Marmontel não é muito extensa, continuam sendo de grande valia os seguintes levantamentos bibliográficos, publicados na década de sessenta: VALETTE 1964; RENWICK 1965. Na última década, a partir da comemoração do bicentenário da morte de Marmontel, estudos sobre ele ganharam novo impulso. Cf. especialmente JOURDAN; MEERHOFF 1999; RENWICK 2001; WEGNER 2003.

${ }^{2} \mathrm{~A}$ obra foi muito apreciada em sua época e mesmo ao longo do século XIX. Morellet não poupou elogios: "Os Elementos de literatura são nesse gênero o mais bem feito livro que existe em qualquer língua". Saint-Beuve reforça o coro quando escreve que "Não há nada de melhor do que seus artigos na Enciclopédia que foram recolhidos sob o título de Elementos de literatura". Cf. MORELLET 1822, p. 499; SAINT-BEUVE s. d., p. 536. Saint-Beuve, Brunetière e Riballier, deixando clara a marcada mudança de gosto ocorrida após a Revolução, irão defender, aliás, que, de toda a obra de Marmontel, apenas as Memórias continuariam a merecer leitura. Cf. SAINT-BEUVE s. d., p. 515; BRUNETIÈRE 1911, p. 247; RIBALLIER 1920, p. 512. Análises contemporâneas da atuação de Marmontel como teórico da literatura podem ser encontradas em SAINT VICTOR 1971; CARDY 1982.
} 
confirmam em outros verbetes da obra, como no caso daquele sobre a arenga histórica no qual Marmontel discute, retomando um tópico já bastante trabalhado por historiadores anteriores (Cf. GRAFTON 2007), a conveniência ou não de o historiador "ceder a palavra a seus personagens" (MARMONTEL 1825a, p. $1){ }^{3}$ isto é, imaginar como teriam sido os diálogos entabulados por eles em acontecimentos históricos cruciais.

No verbete "História", Marmontel, aproveitando as leituras de Horácio, Cícero e Tito Lívio (Cf. MARMONTEL; TOURNEAUX 1891, p. 19) que realizara na juventude, quando ainda estudava com os jesuítas, ocupa-se principalmente com questões de estilo de escrita histórica e com o posicionamento ético do historiador perante os fatos narrados. Nesse sentido, sua abordagem difere bastante da empregada por Voltaire no verbete "História", este último, sim, publicado na Enciclopédia. Enquanto Marmontel se detém com mais vagar em exemplos de estilo tirados de Tácito e Tito Lívio, apontando as fragilidades da escrita contemporânea da história, sem cogitar o uso de outras fontes pelo historiador que não as textuais, Voltaire se ocupa com a distinção entre história e mito (Cf. VOLTAIRE 1765, p. 220-221) e com a especulação sobre a utilidade ou não dos objetos de antiquário, dos monumentos, como fontes para a pesquisa histórica. ${ }^{4}$ Também põe em xeque a expectativa de certeza na história: "Toda certeza que não é demonstração matemática não passa de uma extrema probabilidade. Não há outra certeza histórica" (VOLTAIRE 1765, p. 223). Marmontel reforça essa afirmação, pois compartilha com Voltaire a leitura atenta da obra de Pierre Bayle. Pelo menos mais um ponto Marmontel e Voltaire apresentam em comum em seus respectivos verbetes: a ideia de que a história é uma arte do espírito e de que, como tal, poucos são os artistas capazes de bem executá-la.

A concepção eminentemente textual de história proposta por Marmontel -, talvez um bom representante do que R. G. Collingwood (1994) chamava, em tom irônico, de historiador de cola e tesoura - apresenta, no entanto, algumas peculiaridades interessantes. Uma delas é a tentativa de definição das características específicas da escrita histórica. A tarefa do historiador, antes de mais nada, difere da do poeta. Aquele busca a verdade, enquanto este objetiva seduzir através da exploração do patético. O historiador ideal é cosmopolita, sem paixões, nem mesmo as nacionalistas (exceção aberta, talvez, à paixão pelo combate à tirania e à mistificação), pois apenas assim atingirá o seu objetivo, que é a elaboração de um relato o mais próximo possível da verdade pela escolha de eventos de interesse universal que, ao mesmo, tempo despertem a atenção e sirvam como exemplo, dentro do espírito da historia magistra vitae (Cf. KOSELLECK 2006, p. 42). O historiador é também escritor, e Marmontel recorre significativamente aos dois termos para se referir a ele. Como escritor,

\footnotetext{
3 Todas as traduções de trechos de obras cujos títulos constam em francês nas "Referências" foram realizadas pela autora.

${ }^{4}$ Para Voltaire, um monumento se torna fonte confiável apenas quando um documento contemporâneo confirma as informações que ele contém. Ele indica ainda os três únicos conjuntos de "peças de antiquário" que julga conter informações fidedignas: os registros astronômicos da Babilônia (enviados à Grécia por Alexandre e consultados por Ptolomeu para o Almagesto); o eclipse central do Sol calculado na China; e os mármores de Arundel, particularmente as crônicas de Paros (c. 260 a.C.), que contam a história de Atenas entre 1582 e 354 a.C. Cf. VOLTAIRE 1765, p. 221.
} 
o historiador precisa ainda ter consciência do grau de conhecimento histórico de seus leitores potenciais: o modelo de escrita de Tito Lívio, por exemplo, é recomendado àqueles com pouco conhecimento, e o de Tácito, aos já iniciados.

Tornou-se uma constante crítica afirmar que Marmontel apenas organizou as ideias sobre a história correntes em seu tempo. ${ }^{5}$ Brunetière (1849-1906) chegou a escrever que "Quando se trata de Marmontel [...] nele não podemos levar a sério nem o filósofo, nem o político, nem o historiador" (BRUNETIÈRE 1911, p. 267). Saint-Beuve (1804-1869) definiu ainda, com alta dose de humor, uma característica narrativa de Marmontel que o tornaria pouco confiável como historiador: essa tendência a alterar o teor dos acontecimentos narrados, "o hábito de ver as coisas de um modo um pouco diferente do que são, de pintá-las com um certo colorido benevolente e amolecido que não é sua cor justa [...], essa disposição do autor a Marmontelizar a natureza" (SAINT-BEUVE s. d., p. 524). Nas últimas décadas, no entanto, tudo indica que a sorte de Marmontel, até então considerado um "escritor de segunda ordem" (CARDY 1978), começou a mudar. Após a chamada "virada linguística", quando as discussões sobre o caráter literário e ficcional da escrita da história ganham fôlego, uma volta aos Élemens de Littérature de Marmontel e, especificamente, ao verbete "História" aqui apresentado pode, quem sabe, oferecer novos argumentos para o pensamento sobre os limites nem sempre claros entre a escrita da literatura e aquela da história.

\section{Referências bibliográficas}

BRUNETIÈRE, Ferdinand. Les Mémoires d'un homme heureux. In: Études Critiques sur I'Histoire de la Littérature Française. Sixième Série. 3a ed. Paris: Librairie Hachette, 1911, p. 247-268.

CARDY, Michael. The literary career of Jean-François Marmontel. Oxford: Voltaire Foundation, 1982.

. The Rehabilitation of a Second-rate Writer: Jean-François Marmontel. University of Toronto Quarterly 48, p. 163-171, 1978.

COLLINGWOOD, R. G. A ideia de História. Lisboa: Editorial Presença, 1994.

GRAFTON, Anthony. What Was History? The Art of History in Early Modern Europe. Cambridge: Cambridge University Press, 2007.

JOURDAN, Annie; MEERHOFF, Kees. Mémorable Marmontel: 1799-1999. Amsterdam; Atlanta: Éditions Rodopi, 1999.

KOSELLECK, Reinhart. Futuro passado: contribuição à semântica dos tempos históricos. Rio de Janeiro: Contraponto/ Ed. PUC-Rio, 2006.

LENEL, Scipion. Un homme de lettre au XVIIIe siècle: d'après des documents nouveaux \& inédites. Paris: Librairie Hachette, 1902. 
MARMONTEL, Jean-François. Harangue historique. In: Éléments de

Littérature. T. III. Paris: Verdière Libraire, 1825a, p. 1-9. . Histoire. In: . Éléments de Littérature. T. III. Paris: Verdière Libraire, 1825b, p. 42-82.

; TOURNEAUX, Maurice (Ed.). Mémoires de Marmontel. Paris: Librairie des Bibliophiles, 1891. T. I, II, III.

MORELLET, André. Sur Marmontel. In: Mémoires sur le dixhuitième siècle et sur la Révolution Française. $2^{a}$ ed. Paris: Baudouin, 1822, p. 498500. T. II.

RENWICK, John. Jean-François Marmontel: 1723-1799: dix études. Paris: H. Champion, 2001. . Marmontel: A Bibliographical Addition 1900-1960. MLN, Baltimore, v. 80 , n. 50, p. 623, dec. 1965.

RIBALLIER, L. Un adversaire des Encyclopédistes. La querelle de «Bélisaire». Revue des Études Historiques, Paris, Année 86, p. 505-527, oct. déc. 1920.

SAINT-BEUVE, C. A. Mémoires de Marmontel. In: Causeries du Lundi. Tome quatrième. $4^{a}$ ed. Paris: Garnier Frères, s. d., p. 515-538.

SAINT VICTOR, Pierre. Le concept de littérature dans I'Encyclopédie. The French Review, Carbondale, v. XLIV, n. 6, p. 1057-1066, may 1971.

VALETTE, Rebecca M. Marmontel: A Comprehensive Bibliography 1900-1960. MLN, Baltimore, v. 79, n. 50, p. 552-553, dec. 1964.

VOLTAIRE. Histoire. In: Encyclopédie, ou Dictionnaire raisonné des Sciences, des Arts et des Métiers, par une Société de Gens de Lettres. Neufchastel: Chez Samuel Faulche \& Compagnie, Libraires \& Imprimeurs, 1765, p. 220-225. Tome Huitième (H-IT).

WEGNER, Jacques. Marmontel: une rhétorique de I'apaisement. Louvain, Paris \& Dudley: Éditions Peeters, 2003. 